\title{
WORK FROM HOME, MENTAL HEALTH AND EMPLOYEE NEEDS: A PILOT STUDY IN SELECTED INFORMATION TECHNOLOGY ORGANIZATIONS IN INDIA
}

\author{
Phadnis S1, Sengupta S2, Chakraborty A3 \\ 1.2. Healthcare Management, Goa Institute of Management, Goa, India \\ 3. International Crops Research Institute for the Semi-Arid Tropics, Patancheru, Hyderabad, India.
}

Correspondence: supriya.phadnis@gim.ac.in

\begin{abstract}
INTRODUCTION:

The Coronavirus (COVID-19) pandemic has impacted the economy and has resulted in changes to the working arrangements of employees who are based at home and may continue to work from home (WFH). Organizations are expected to develop an inclusive policy for their employees to promote mental health whilst working from home. The aim of this study was to document the impact of WFH on mental health and determine the expectations of employees from their organizations regarding occupational health policy.
\end{abstract}

\section{METHODOLOGY:}

A cross-sectional study was conducted on the impact of work from home on mental health and to document the mental health support needs of employees. Google form was floated through social media platform to receive the responses. A total of 74 responses were received. Descriptive analysis was conducted using Microsoft Excel, while qualitative answers were manually analysed.

\section{RESULTS:}

About $67 \%$ employees ( $n=45$ ) mentioned that their workload has increased significantly during work from home. Thirty five percent $(n=26)$ felt lonely and lost and $47 \%(n=34)$ felt disconnected from the real world, indicating the mental health impact of work from home. Fifty three percent employees $(n=40)$ mentioned that there were no efforts made by their organization to reduce the mental health impact of work from home.

\section{CONCLUSION:}

The results of this study indicate that there is an urgent need to create a comprehensive occupational health and safety policy inclusive of strategies to improve mental health by the organizations in light of "work from home" as a "new-normal".

\section{KEYWORDS}

Work-from-home, Mental health, COVID-19, Occupational health and Safety. 
INTRODUCTION

COVID-19 began as an unprecedented global health challenge but quickly transformed into a development crisis. [1,2] Governments across the world implemented a range of measures to contain the spread of the virus. [3] Stringent measures like lockdowns and limitations on travel were adopted as the primary strategy to save lives, but they came with huge socioeconomic ramifications. The pandemic has changed the fundamental principles of work globally with over $\mathbf{4 0 0}$ million full-time jobs were lost in the second quarter of 2020. [4] In terms of work environment, employees who are working in the sectors where remote working is possible, home has become the new workplace and will be a long-term scenario given the potential circulation of COVID-19 virus in the community. $[5,6]$

Work from home (WFH) is not a new concept in the world of work. WFH, however, was widely accepted in the IT sector in the early 2000s with improved internet connectivity; when workers could easily WFH to avoid commuting, provide flexibility in schedules, and achieve a better work-life balance. [7] In recent times, WFH has become easier with the help of new emerging technology that has revolutionized the work pattern significantly. [8, 9] There are certain noted benefits of WFH. It saves the time required for daily commuting, offers more flexibility for employees to manage family time. WFH also allows employees to work flexibly when they are most productive and also reduces distractions by the co-workers. [7, 10-11] The negative impact on health, especially mental health due to certain issues such as blurring boundaries between work and family, extended work hours, lack of social interaction and limited support from the organization cannot be neglected. [12] In light of current pandemic when individuals are reacting through a sense of fear, anxiety, loss of connection with society, [13] the new reality of changing pattern of work can further affect the mental wellbeing of individuals.

Although limited, the available literature indicates the complexity of WFH impact on employee's wellbeing. Employees appear less connected; projects take longer to be completed. In addition to this, lack of separation between work and life, along with continuous communication and long work hours are the top workplace stressors. [14] Another article suggested that physical and mental wellbeing was significantly affected with WFH and was associated with several influencing factors such as exercise, increased food consumption, lack of communication with co-workers, distractions while working, changed work hours and lack of proper workstation set-up. [15]

Thus, while work from home has been proven as a successful model to reduce transmission of the COVID-19 among the working population and protecting physical health of the population, emerging evidence has indicated that it leads to several mental health related issues such as blurring of boundaries between work and personal life, unequal burden of work and rising stress. [15] Investigating the mental health impact and expectations of employees to improve the mental health wellbeing during WFH is highly required in recent times. Especially employers need insights on how to provide best working environment to their employees to avoid negative impact of WFH and to improve the work productivity. Against this background, the present paper seeks to understand the mental health impacts of working from home among a cross-section of population who embarked on working from home in India.

\section{METHODS}

Study Design, setting and participants: This study used cross-sectional study design to elicit the information from the participants. The study was set in India. Participants of the study are from several states of the country. The inclusion criteria was a) working in the field of IT b) working from home for minimum of 3 months $C$ ) providing verbal consent to participate in the study. The exclusion criteria were a) those who are currently not working in the IT sector b) those who refused to give consent to participate in the study.

Study Instrument: The study instrument was anonymous, online questionnaire developed using the google forms. The questionnaire included questions on demographics of participants, history of WFH, perception about self-mental well-being during WFH, organizational initiatives to provide comfortable work environment and their expectations from the organization to further reduce the negative impact of WFH on mental well-being. Questions related to demographics of participants were of multiple-choice nature. Likert scale questions were asked to understand the mental well-being of participants. In addition to these closed ended questions, one open ended question was 
also included to understand the impact of WFH on the mental health of participants. In order to elicit the information regarding the efforts made by the organization to maintain the well-being of participants and their expectations from the organization, open ended questions were included in the questionnaire. The average duration to complete the total questionnaire was about 12 to 15 minutes per participant.

Ethical considerations: Participation in the study was voluntary. Oral consent of participants was sought before sending the questionnaire. All the data was collected anonymously. Participants were assured that the data will be strictly used for research purpose and will not be exposed to any other purpose.

Data Collection: Participants were recruited through emails and social media platforms, with snowball sampling used to extend the recruitment process. Eligible participants were identified by an initial screening question based on the inclusion criteria and their willingness to participate in the study. A total of 107 responses were received to this initial screening, of which 21 did not want to participate in the study, while 12 did not complete the screening questionnaire. Thus, a total of 74 participants were recruited in this study. The link for google questionnaire was provided to these participants after the oral consent was sought. The response was automatically received by the authors. The data was collected in the month of March 2021.
Data analysis: Data obtained through the closed ended questions was analyzed using Microsoft excel. Likert based questions contained the options such as 'Strongly agree', 'Agree', 'Neutral', 'Disagree', and 'Strongly disagree'. While some questions have the options such as 'Always', 'Almost always', 'Sometimes', 'Almost never' and 'Never'. Descriptive statistics was used to describe the mental wellbeing of participants based on these Likert scale-based responses. The data obtained through open ended questions was analyzed manually to understand what do the participants feel about the efforts taken by their organization to improve the mental health as well as their expectations from the organization to further improvement.

\section{RESULTS}

\section{DESCRIPTION OF PARTICIPANTS:}

Table 1 describes the general characteristics of the participants. Out of total sample $(n=74)$, there were $58 \%$ males ( $n=43$ ). About $51 \%$ of the total sample belonged to age group of $31-40$ years $(n=38)$ while $59 \%(n=44)$ were married. It was seen that $30 \%(n=22)$ and $46 \%(n=34)$ of the participants were junior level and mid-level management employees respectively. When the question related to how long they are working from home was asked, almost $56 \%$ $(n=41)$ mentioned that they were working from home only during the COVID-19 pandemic. All senior level employees on the contrary were working from home regularly even before the pandemic

TABLE 1: GENERAL CHARACTERISTICS OF PARTICIPANTS

\begin{tabular}{|l|l|}
\hline DESCRIPTION & \multicolumn{1}{|l|}{ NUMBER (\%) } \\
\hline Total sample & $74(100 \%)$ \\
\hline Sex & \multicolumn{2}{|l|}{} \\
\hline Male & $43(58 \%)$ \\
\hline Female & $31(42 \%)$ \\
\hline Age & $26(35 \%)$ \\
\hline $21-30$ years & $38(51 \%)$ \\
\hline $31-40$ years & $10(14 \%)$ \\
\hline $41-50$ years & $25(34 \%)$ \\
\hline Marital status & $44(59 \%)$ \\
\hline Single & $5(7 \%)$ \\
\hline Married & \\
\hline Divorced & $22(30 \%)$ \\
\hline Designation in the current organization & $34(46 \%)$ \\
\hline Junior level & \\
\hline Middle management &
\end{tabular}




\begin{tabular}{|c|c|}
\hline Senior level & $18(24 \%)$ \\
\hline \multicolumn{2}{|l|}{ Years of experience } \\
\hline Less than 5 years & $19(26 \%)$ \\
\hline $6-10$ years & $21(28 \%)$ \\
\hline $11-15$ years & $24(32 \%)$ \\
\hline 16 years and more & $10(14 \%)$ \\
\hline \multicolumn{2}{|l|}{ Working from home since } \\
\hline $1-3$ years & $26(35 \%)$ \\
\hline More than 4 years & $07 \quad(9 \%)$ \\
\hline Only during COVID-19 pandemic & $41(56 \%)$ \\
\hline
\end{tabular}

\section{PERCEPTION OF PARTICIPANTS TOWARDS WORK FROM HOME:}

As table 1 shows that WFH was comparatively new experience for $56 \%(n=41)$ employees, this section describes the overall perception of participants towards WFH. Fig. 1 shows the perception in terms of efforts from organizational level and perceived impact on performance and personal life. The results show that almost $73 \%$ participants $(n=54)$ who reported being strongly agree and agree that the organization made the transition from office to WFH easy and smooth. Although $67 \%$ employees $(n=50)$ replied being strongly agree and agree that WFH increased their workload, they also strongly agreed and agreed to the fact that their quality of work was better due to $\mathrm{WFH}(\mathrm{n}=35,47 \%)$. While $96 \%$ highly agreed to the fact that WFH has reduced their travel time $(n=71)$, the participants also mentioned that their physical exercise has been negatively impacted due to WFH ( $n=58,78 \%)$.

\section{WORK-RELATED CHANGES AND CHALLENGES EXPERIENCED DURING WFH}

Figure 2 describes the changes experienced by the participants both at personal and professional as they began working from home. At the professional level $64 \%$ of participants $(n=47)$ either strongly agreed or agreed that they had become better with time management. However, when the question was asked if they could give more time to their family, it is noteworthy to see that about $13 \%(n=10)$ completely disagreed and $44 \% \quad(n=33)$ remained neutral. Another interesting finding was that almost $37 \%(n=28)$ of participants felt that they have no privacy while almost $28 \%(n=21)$ remained neutral for this question. Forty-seven percent $(n=35)$ participants either strongly agreed or agreed to the statement that they felt disconnected from real world due to $\mathrm{WFH}$ and $30 \%$ remained neutral $(n=22)$. Only about one fourth of the participants however used calming techniques such as meditation to manage stress and stay calm $(n=19)$.

\section{FIGURE 1: PERCEPTION OF PARTICIPAANTS TOWARDS WORK FROM HOME}

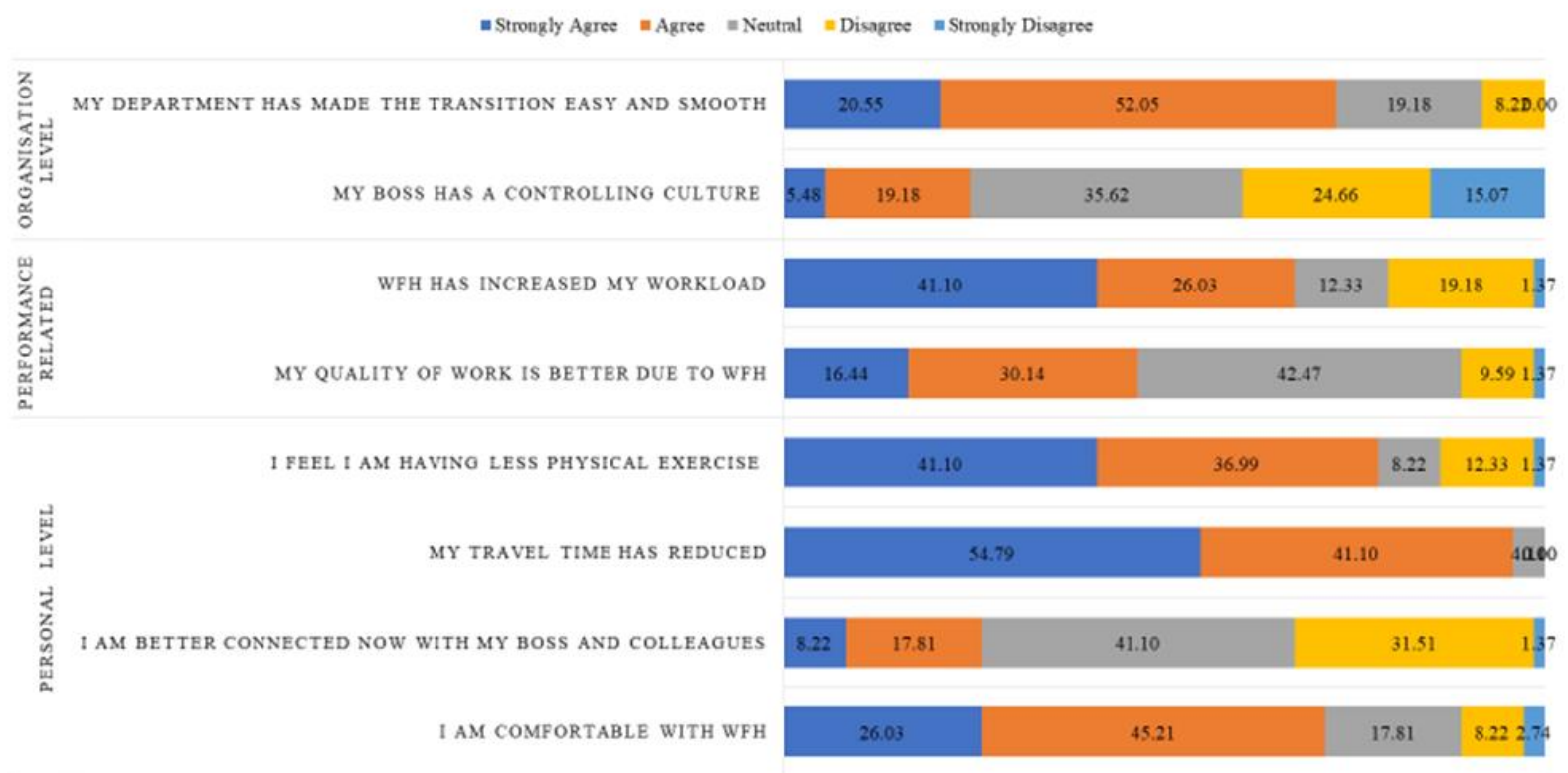




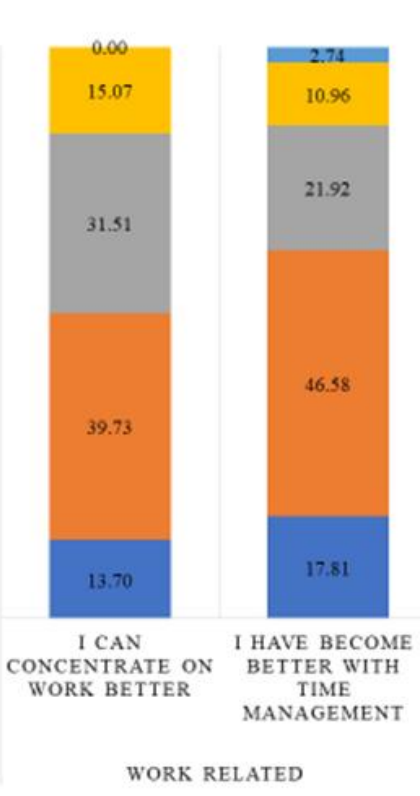

WORK RELATED
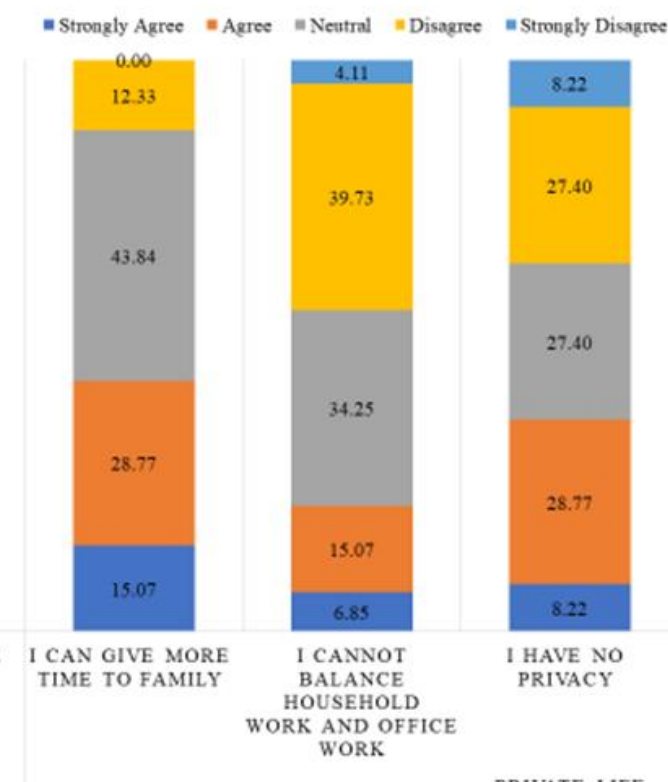

PRIVATE LIFE

\section{STATUS OF MENTAL HEALTH OF EMPLOYEES DURING WFH}

Table 2 shows the responses noted for the questions related to mental well-being of the participants. Although there is a positive trend seen in the overall responses, the proportion of participants mentioning the occurrence of particular issue sometimes in last 30 days is noteworthy. While almost $60 \%(n=44)$ mentioned that they were most productive in last 30 days during $\mathrm{WFH}$, a total of 26 participants $(34 \%)$ however mentioned that they were sometimes productive during WFH as compared to earlier when they used to work from office. Similarly, in terms of negative feelings almost half of the participants sometimes felt stressed, anxious and felt angry and irritated (48\% and $49 \%$ respectively), in addition to $23 \%$ and $22 \%(n=17, n=15$ respectively) participants who were always and almost always stressed, anxious and felt angry and irritated.

In addition to these quantitative responses, participants were also asked an open-ended question to write about the mental health impact of WFH. It was seen that more than half participants ( $n=60,81 \%$ ) used negative words to elicit the impact. The words which appeared frequently in the narratives of the participants include - 'stress', 'angry', 'Ioss of privacy', lonely', 'detached', 'lost', irritated,' social disconnect', 'absence of connect with colleagues' (Fig. 3).

TABLE 2: MENTAL HEALTH OF PARTICIPANTS DURING WFH

\begin{tabular}{|l|l|l|l|l|l|l|}
\hline & & ALWAYS & $\begin{array}{l}\text { ALMOST } \\
\text { ALWAYS }\end{array}$ & SOMETIMES & $\begin{array}{l}\text { ALMOST } \\
\text { NEVER }\end{array}$ & NEVER \\
\hline $\begin{array}{l}\text { Positive } \\
\text { Feelings }\end{array}$ & $\begin{array}{l}\text { I feel cheerful } \\
\text { and relaxed } \\
\text { I have been } \\
\text { most productive }\end{array}$ & 9.59 & 42.47 & 38.36 & 9.59 & 0.00 \\
\hline $\begin{array}{l}\text { Negative } \\
\text { Feelings }\end{array}$ & $\begin{array}{l}\text { I feel stressed } \\
\text { and anxious }\end{array}$ & 1.37 & 21.92 & 47.95 & 5.48 & 0.00 \\
\hline $\begin{array}{l}\text { I feel angry and } \\
\text { irritated }\end{array}$ & 1.37 & 20.55 & 49.82 & 21.92 & 6.85 \\
\hline $\begin{array}{l}\text { I feel lonely and } \\
\text { helpless }\end{array}$ & 4.11 & 16.44 & 31.51 & 31.51 & 6.85 \\
\hline
\end{tabular}




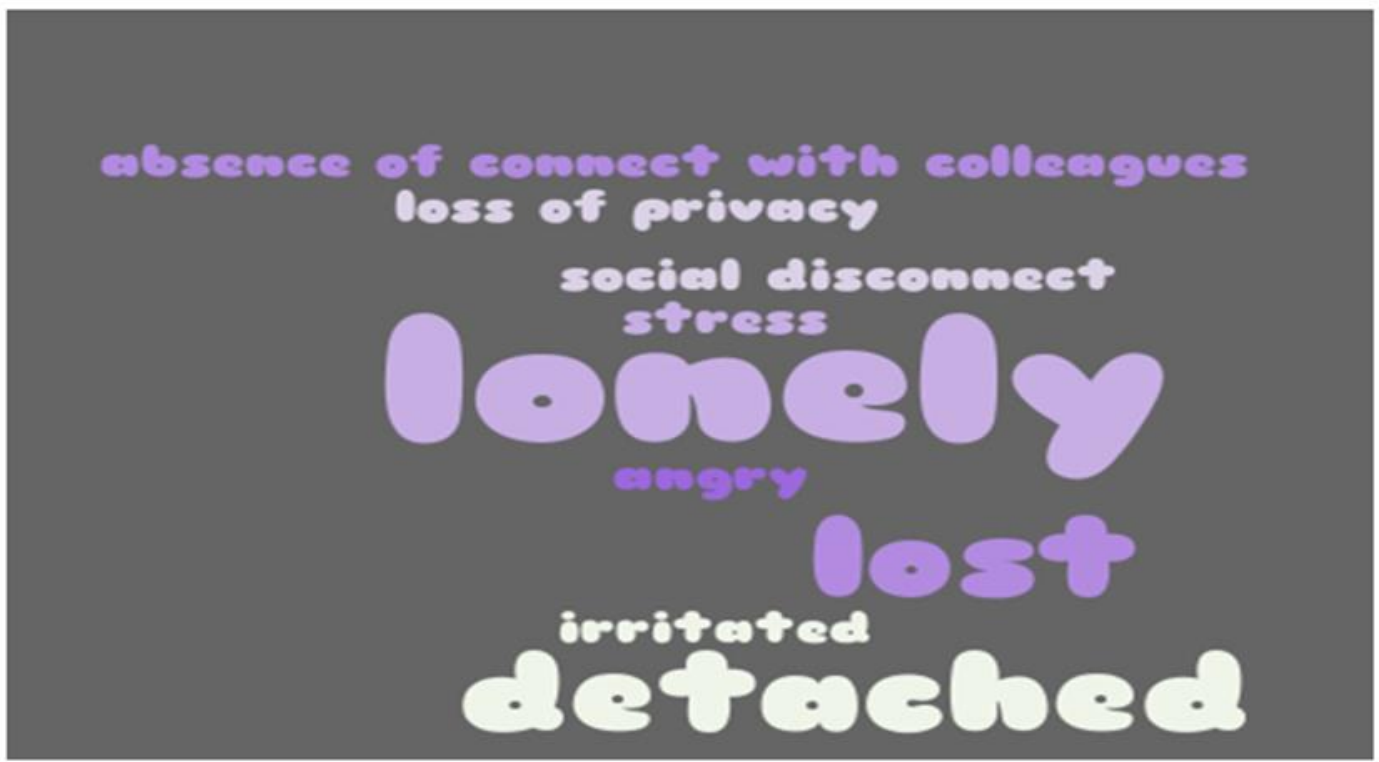

TABLE 3: THEMATIC ANALYSIS OF RESPONSES OF PARTICIPANTS

\begin{tabular}{|l|l|}
\hline THEMES & RESPONSES FROM PARTICIPANTS \\
\hline Emotional issues related to family & I don't get time to play with kids \\
\hline $\begin{array}{l}\text { Emotional issues related to work, } \\
\text { engagement with colleagues }\end{array}$ & $\begin{array}{l}\text { Work preoccupies my mind, so cannot enjoy } \\
\text { There is pending work, feeling of restlessness }\end{array}$ \\
$\begin{array}{l}\text { Loss of collective voice - management has become more } \\
\text { demanding, more aggressive and less accommodating, less } \\
\text { approving }\end{array}$ \\
\hline $\begin{array}{l}\text { Impact on mental health } \\
\text { Fear of the future }\end{array}$ \\
$\begin{array}{l}\text { Stressed, angry, feeling abnormal, loss of privacy, social } \\
\text { disconnect, lonely, alone, detached, } \\
\text { feel weak and lost }\end{array}$ \\
\hline
\end{tabular}

Further, a thematic analysis was done of the responses received from the participants to gain a complete understanding of the additional themes which emerged in the narratives on mental wellbeing. The responses of the participants can be divided into three categories emotional issues related to family, emotional issues related to work and engagement with colleagues and impact on mental health (table 3). It is evident from the thematic analysis that WFH caused a certain amount of mental health issues which also might have psychosomatic consequences.

\section{ORGANISATIONAL INITIATIVES TO PROMOTE MENTAL WELLBEING OF EMPLOYEES}

Although $53 \%$ of participants $(n=39)$, reported that organisations did not take activities to ensure mental wellbeing of their employees, rest of the participants $(n=35$, $47 \%$ ) narrated the initiatives undertaken by their organisations to take care of their emotional wellbeing. These activities comprised of arranging sessions with counsellors, webinars on mental health, launching a helpline, conducting quiz, mind games, online gaming, meditation, stress-related workshop, frequent townhall, greater interaction with colleagues, and continuous 
communication from senior officials. About $38 \%(n=28)$ of the sample were satisfied or moderately satisfied by their organisational initiatives, while and equal share of the participants also expressed displeasure and dissatisfaction about these initiatives to address mental and physical health related concerns.

\section{EMPLOYEES' EXPECTATIONS ABOUT PROTECTION OF MENTAL HEALTH OF WORKERS}

While $34 \%$ of participants ( $n=25$ ) reported that they did not have any expectations from their organisations; rest of the participants have provided suggestions about how organization can ensure better employee well-being and consequently, increase performance of individuals and teams and make workplaces safer and inclusive. Some of the suggestions are; leaders should be empathetic, ensure job assurance and appreciate employees frequently, increase communication with employees, offices can organise yoga/meditation sessions over video calls, conduct webinars on motivation, for making employees feel connected, track employee well-being - conduct mental health-related surveys.

\section{DISCUSSION AND CONCLUSION}

WFH has been implemented as a part of broad public health and epidemiology measure to prevent the spread of COVID-19. Although not a new concept, the WFH was adapted rapidly all over the world and will likely remain as a long-term measure to manage physical distance required to curb the spread of infection. In light of availability of limited literature on the impact of WFH on the mental health of employees, this study aimed at documenting the mental health status as well as activities undertaken to mitigate the impact of WFH on overall health and needs of employees to further alleviate the suffering.

The results of this study commensurate with the results of several other publications which mentioned the impact of WFH in terms of increased workload, thinning the line between professional and family life and also negative impact on physical health especially in term of lack of physical exercise (15). It is pertinent to add that even though this was a pilot study; it clearly highlights the impact of the prevailing pandemic on health of the employees. However, the findings from the pilot, underscore the need, for expanding the scope of the study across the country, in order to develop a robust Work from Home policy. As mentioned in the earlier section that COVID-19 pandemic has resulted into a complex web of emotions such as uncertainty, anxiety, feeling of loneliness the changed workplace environment is certainly adding to the negative feelings by disconnecting people from each other, lack of communication with co-workers. The result of this study shows that the radical change in work environment absence of all forms of physical interactions between colleagues - led to a sense of isolation and disconnectedness from the real world for many participants. The virtual work environment, increased screen time, the pressure to be continuously available heightened stress, anxiety and insecurity. The cumulative effects of working virtually for a prolonged period of time had a detrimental impact on the emotional well-being of the employees.

Although certain measures were reported to be undertaken to provide better work environment by the organizations, participants expected more contribution of the organization to provide decent work (SDG 8 goal) environment while WFH. The study indicates that there should be a greater dialogue on how WFH impacts mental health of employees. Data suggests that organisations should develop a checklist to periodically monitor the physical and mental health of the employees. Periodic monitoring will help organisations gauge the actual physical and mental health needs of the employers in remote working conditions. This assessment will also help organisations to plan better interventions to reduce stress, anxiety, isolation and panic; rather than organise ad hoc, isolated events. The study also intended to see if there is any difference in the status of mental health and response to changing work space and environment as per the gender of respondents. However, there was no significant difference that was observed.

The study has few limitations. Firstly, due to its pilot nature, the sample size is small. Secondly, the COVID-19 pandemic had created restrictions for field-based data collection. This impediment in data collection made it difficult to adopt a structured sampling and get a countrywide representation. Hence, participants were selected through purposive sampling completed in online mode through social media connections. Thirdly the results of this study can be strengthened with further national investigations. In conclusion, this study highlights factors that impact employee's mental health well-being while working from home and provides a foundation to the organizations for considering how to best rework their occupational and safety management process to create a positive WFH experience. 


\section{References:}

1. The Lancet Public Health. COVID-19 puts societies to the test. Lancet Public Health. 2020;5(5):e235.

2. Douglas $M$, Katikireddi SV, Taulbut $M$, McKee $M$, McCartney $G$. Mitigating the wider health effects of covid-19 pandemic response. BMJ. 2020;369:m1557.

3. International Labour Organisation (2020a). An employer's Guide on working from home in response to the outbreak of COVID-19. Geneva: International Labour Organisation,

https://www.ilo.org/wcmsp5/groups/public/--ed_dialogue/---

act_emp/documents/publication/wcms_745024.pdf Accessed 4 May 2021.

4. International Labour Organisation (2020b). Issue paper on COVID-19 and fundamental principles and rights at work. Geneva: International Labour Organisation. https://www.ilo.org/wcmsp5/groups/public/--ed_norm/--ipec/documents/publication/wcms 757247.pdf .Accessed 4 May 2021.

5. Belzunegui-Eraso A, Erro-Garcés A. Teleworking in the context of the Covid19 crisis. Sustainability.

2020;12(9):3662

6. Shimazu A, Nakata A, Nagata T, Arakawa Y, Kuroda S, Inamizu N, et al. Psychosocial impact of COVID-19 for general workers. J Occup Health. 2020;62(1):e12132.

7. Samani SA. The impact of personal control over office workspace on environmental satisfaction and performance. J Soc Sci Humanit 2015; 1:163-172.

8. Eurofound and the International Labour Office. Working anytime, anywhere: the effects on the world of work. Luxembourg: Publications Office of the European Union; 2017. https://www.raco.cat/index.php/IUSLabor/article/ download/333024/423859.Accessed 4 May 2021.

9. Henke RM, Benevent R, Schulte P, Rinehart C, Crighton $\mathrm{K}$, Corcoran M. The effects of telecommuting intensity on employee health. Am J Health Promot. 2016;30(8):604-12

10. Tavares Al. Telework and health effects review. Int J Healthc 2017; 3:30.

11. Bouziri H, Smith DRM, Descatha A, Dab W, Jean K. Working from home in the time of COVID-19: how to best preserve occupational health? Occup Environ Med 2020; 77:509-510.

12. Allen TD, Golden TD, Shockley KM. How effective is telecommuting? Assessing the status of our scientific findings. Psychol Sci Public Interest. 2015;16(2):40-68.
13. Pan K.Y., Kok A.A.L., Eikelenboom M., Horsfall M., Jörg F., Luteijn R.A. The mental health impact of the COVID-19 pandemic on people with and without depressive, anxiety, or obsessive-compulsive disorders: a longitudinal study of three Dutch case-control cohorts. Lancet Psychiatry. 2021;8(2):121-129.

14. Spataro, Jared (2020). A Pulse on Employees' Wellbeing, six months into the pandemic. Microsoft 365. https://www.microsoft.com/en-us/microsoft365/blog/2020/09/22/pulse-employees-wellbeing-sixmonths-pandemic/ Accessed 4 May 2021.

15. Xiao, Yijing; Becerik-Gerber, Burcin DDes; Lucas, Gale PhD; Roll, Shawn C. PhD Impacts of Working From Home During COVID-19 Pandemic on Physical and Mental Well-Being of Office Workstation Users, Journal of Occupational and Environmental Medicine: March 2021 - Volume 63 - Issue 3 - p 181-190 